\title{
LETTERS
}

\section{Principles for screening: Too few concerns for informed consent and shared decision-making?}

Dobrow and colleagues must be commended for their comprehensive but simple review of screening principles in three sections: disease/condition, test/ intervention and program/system. ${ }^{1}$ The latter is frequently overlooked. Screening is far more than a test for a disease; it should be considered a public health program-with quality assurance built in. Sadly, resources are a constraint for implementing these principles. However, principle 9 "informed choice, promoting autonomy and protecting [participants'] rights" is simple and inexpensive to implement. ${ }^{1}$

There is good evidence that pictographs with absolute numbers (using a consistent denominator, such as 1000 screened), time frames and visuals employing the same scale for information on gains and losses of the options can contribute to shared decision-making. ${ }^{2}$ Belgium has been using pictographs since 2013 for breast cancer screening. In contrast, the National Cancer Institute in France, and other health agencies, flying in the face of ethics, has not provided such information to patients despite many public requests since 2012 , with the most recent one supported by the main consumers nongovernmental organization in France. ${ }^{3}$ Worse, this has been combined with data torture to deny the possibility of overdiagnosis, suppression of scientific debate on breast cancer screening ${ }^{4}$ and the inclusion of screening uptake in France's 4P4 quality improvement scheme that promotes the propagation of unbalanced information for patients: "the general practitioner draws the patient's attention to the benefits of (breast cancer) screening ... produces positive information about screening ... which naturally falls within the scope of mere monitoring ... in order to remove his patients' reticence." ${ }^{5}$

\section{Alain Braillon MD}

Senior consultant, University Hospital, Amiens, France

\section{Philippe Nicot MD}

Family physician, Panazol, France

Cécile Bour MD

Radiologist, Clouange, France

- Cite as: CMAJ 2018 September 17; 190:E1115. doi: 10.1503/cmaj.69766

\section{References}

1. Dobrow MJ, Hagens V, Chafe R, et al. Consolidated principles for screening based on a systematic review and consensus process. CMAJ 2018; 190:E422-9.

2. Braillon A, Bewley S. Shared decision-making for cancer screening: visual tools and a 4-step method. JAMA Intern Med 2015;175:1862.

3. Cancer du sein - L'INC a fourni aux femmes une information incomplète et partiale sur les avantages et les inconvénients à suivre le dépistage organisé. Que Chosir; 2018 Apr. 6. Available: www.quechoisir.org/action-ufc-que-choisir-cancer -du-sein-l-inca-fournit-aux-femmes-une-information -incomplete-et-partiale-sur-les-avantages-et-les -inconvenients-a-suivre-le-depistage-organise -n53673/ (accessed 2018 Apr. 20).

4. Braillon A, Bewley S. Why use Markov simulation models for estimating the effect of cancer screening policies when randomised controlled trials provide better evidence? Stat Methods Med Res 2012;21:217-8.

5. Braillon A, Nicot P. Cancer screening and informed consent. A new French exception? Prev Med 2011;53:437.

Competing interests: None declared. 